\title{
Article \\ Preparation of a Molecularly Imprinted Film on Quartz Crystal Microbalance Chip for Determination of Furanic Compounds
}

\author{
Wei-Liang Lin ${ }^{1}$, Chung-Yin Lin ${ }^{2,3, *}$ and Dar-Fu Tai ${ }^{1,4, *}$ \\ 1 Department of Chemistry, National Dong Hwa University, Hualien 97403, Taiwan; usanawes@gmail.com \\ 2 Medical Imaging Research Center, Institute for Radiological Research, Chang Gung University, \\ Taoyuan 33302, Taiwan \\ 3 Department of Nephrology and Clinical Poison Center, Chang Gung Memorial Hospital, \\ Taoyuan 33302, Taiwan \\ 4 Department of Life Science and Institute of Biotechnology, National Dong Hwa University, \\ Hualien 97403, Taiwan \\ * Correspondence: winwood7@mail.cgu.edu.tw (C.-Y.L.); dftai@gms.ndhu.edu.tw (D.-F.T.); \\ Tel.: +886-3-2118800 (ext. 3865) (C.-Y.L.); +886-3-890-3579 (D.-F.T.)
}

Citation: Lin, W.-L.; Lin, C.-Y.; Tai, D.-F. Preparation of a Molecularly Imprinted Film on Quartz Crystal Microbalance Chip for Determination of Furanic Compounds. Chemosensors 2021, 9, 338. https://doi.org/ $10.3390 /$ chemosensors9120338

Academic Editors: Aránzazu Mendía and Miriam Trigo-López

Received: 28 October 2021

Accepted: 30 November 2021

Published: 1 December 2021

Publisher's Note: MDPI stays neutral with regard to jurisdictional claims in published maps and institutional affiliations.

Copyright: (c) 2021 by the authors. Licensee MDPI, Basel, Switzerland. This article is an open access article distributed under the terms and conditions of the Creative Commons Attribution (CC BY) license (https:// creativecommons.org/licenses/by/ $4.0 /)$.

\begin{abstract}
The structural preferences of furanic compounds were studied using a combination of a molecularly imprinted film (MIF) on a piezoelectric-quartz chip. The furanic compounds and their derivatives were used as the templates. Owing to their similar heterocyclic structures, it is difficult to verify the structural differences between the templates. Therefore, a new cross-linker (Methacr-LCys-NHBn) 2 , was employed to generate a platform on a quartz crystal microbalance (QCM) chip. The cross-linker self-assembled to link the surface of the chip to copolymerize with other functional monomers. A layered film with chiral hydrophobicity and rigidity was thus fabricated. Subsequently, Acr-L-Ser-NHBn was utilized as a chiral monomer to construct MIF on a QCM chip. Forcomparison, we synthesized a more hydrophobic monomer, Methacr-L-Ser-NHBn, to enhance the binding ability of the MIF. The QCM flow injection system was handled in an organic solvent system. The proportion of the monomers was adjusted to optimize the recognition ability of these films. As the binding ability of the MIF toward model templates and structurally-related furanic compounds was improved, a MIF derived from 2-furaldehyde (FUL) achieved a lower detection limit (10 ng/mL). The binding properties of MIFs prepared against furanic compounds exhibited strong similarities to the binding properties of other compounds with heterocyclic ring structures. For example, 2-furaldehyde is very similar to 2-formylthiazole, 2-acetylfuran is similar to 2-acetylthiazole, and 2-furfuryl alcohol is similar to imidazole-2-methanol. Such recognition ability can help distinguish between the structural counterparts of other small heterocyclic compounds.
\end{abstract}

Keywords: molecularly imprinted films; quartz crystal microbalance; heterocyclic rings; structural selection; furanic compounds

\section{Introduction}

Biological systems use binding modularity to achieve high selectivity, which is an important outcome in synthetic chemistry [1]. It is possible to create molecular recognition sites by the combination of several complementary weak interactions between biological binding sites and the molecules to be bound, achieving efficient catalysis or response processes [2]. Structure-based design is perhaps the most elegant approach to discovering biomimetic compounds that exhibit high specificity and efficiency. For example, with the dissociation constant $\left(\mathrm{K}_{\mathrm{d}}\right)$, we can assess the binding affinity of ligands to receptors; likewise, with the maximal binding capacity $\left(\mathrm{B}_{\max }\right)$, we can assess the maximum amount of ligand capable of binding specifically to receptors, along with other topological, geometrical, and physicochemical components [3].

Molecularly imprinted films (MIFs) consist of synthetic recognition elements for various analytes ranging from small molecules to large biomacromolecules [4]. MIFs are 
a result of the effort to create artificial counterparts to natural macromolecular binding molecules in polymeric matrix films, when the molecules are complementary in size, shape, and functional group orientation to the template molecule $[5,6]$. The preparation of a MIF involves the copolymerization of functional and cross-linking monomers in the presence of a molecular template. After removal of the template, the cavities of the polymeric matrix film, serving as the recognition sites, present selectivity-providing interactions between the template and functional monomers through the use of hydrogen-bonding, dipole-dipole and ionic interactions $[7,8]$. The quartz crystal microbalance (QCM) is a simple, cost-effective, mass-sensing gravimetric sensor based on the resonant oscillations of a piezoelectric quartz crystal, which is associated with binding reactions and which results in a frequency decrease $[9,10]$. Combining the use of MIF with QCM. MIF-QCM sensors to enable the performance of recognition and discriminating functions, which are helpful in the design, synthesis, and testing of molecular assemblies via the fabrication of biomimetic structures is a very successful approach $[7,11,12]$. In addition, neither of the modalities requires specific storage conditions, the degradation reaction in each modality is in principle unrestricted, and the flow process with organic solvents is also feasible [13,14].

If an MIF exhibits binding properties toward a target molecule, the corresponding MIF will present a significant imprinting effect via frequency changes. In this regard, it is becoming popular to analyze furanic compounds derived from sugars in the food industry $[15,16]$. Several furanic compounds that can obtain from the degradation of cellulose fiber in transformer oil are 2-furaldehyde (FUL), 2-furfuryl alcohol (FOL), 5hydroxymethyl-2-furaldehyde (HMF), 5-methyl-2-furaldehyde (MEF), and 2-acetylfuran $(\mathrm{ACF})[17,18]$. However, a more sophisticated procedure is necessary for detecting these compounds when the detection process involves HPLC or gas chromatography mass spectrometry (GC/MS) instruments (e.g., ASTM D5837 Method D 5827, IEC Method 61198) [17-19]. These techniques are quite tedious, requiring the extraction of substances from samples before the injection of compounds onto the chromatographic column. MIFQCM sensors thus offer a means of producing adducts that enable small molecules to bind to one another $[15,16,20]$ to select a suitable model template for a large molecule, which has usually been available based on X-ray scattering structure in the past [21-24]. However, to increase the structural selectivity and sensitivity in analyte binding for small molecules, not much can be done. A more general approach based on structure similarity can be attempted when the pure natural substrate is not available [22].

The current study presents the results of our thorough investigation into a new crosslinker (Methacr-L-Cys-NHBn) ${ }_{2}$ as it concerns the development of an impressively rigid platform. A new "chiral monomer"-containing hydroxyl group (Methacr-L-Ser-NHBn) can facilitate the construction of a high-performance MIF and can enhance the hydrogen bonding properties of these films. The relationships between optimal composition, film hydrophobicity, and binding properties are demonstrated, and strategies are presented for constructing a high-performance MIF. As for our study's model template, we chose commonly prescribed furanic compounds derived from sugar. The presence of the chiral center on the MIF helps to produce the exact orientation of the hydrogen bonding.

\section{Materials and Methods}

\subsection{Reagents and Equipment}

(Boc-L-Cys-OH) 2 , Boc-L-Ser-OH, acrylamide, and papain were purchased from SigmaAldrich (St. Louis, MO, USA). N-Benzylacrylamide and $N, N$-ethylene bisacrylamide (EBAA) were from Lancaster (Lancashire, UK). Methacryloyl chloride, 2-furfuryl alcohol (FOL), 5-hydroxymethyl-2-furaldehyde (HMF), 5-methyl-2-furaldehyde (MEF), 2furaldehyde (FUL), and 2-acetylfuran (ACF) were obtained from Acros Organics (New Jersey, USA). All other chemicals were of reagent grade and purchased from Merck AG. (Darmstadt, Germany). The QCM chip, with a reproducibility of $\pm 0.1 \mathrm{~Hz}$, was obtained from Tai-Yi Electronic Co. (Taipei, Taiwan). The QCM consisted of an 8-mm-diameter disk made from an AT-cut 10-MHz quartz crystal with gold electrodes on the crystal's two 
sides (diameter, $4.2 \mathrm{~mm}$; area, $13.85 \mathrm{~mm}^{2}$ ). Products were measured by using an Intelligent HPLC system equipped with a Vercopak $\mathrm{C}_{18}$ column (Hitachi Corp., Tokyo, Japan) and characterize using an A-300 AVANCE DPX-300 MHz NMR spectrometer (Bruker, Bremen, Germany).

\subsection{Preparation of Cross-Linking and Functional Monomers}

Scheme 1 presents the synthesis route of both the cross-linking monomer, (MethacrL-Cys-NHBn) ${ }_{2}$, and the functional monomer, (Methacr-L-Ser-NHBn). To form a selfassembled monolayer, we synthesized (Methacr-L-Cys-NHBn) 2 using Boc-L-Ser-OH, DMS, and benzylamine according to the following procedure $[8,25,26]$ : To a solution of Boc-L-Ser$\mathrm{OH}(100 \mathrm{mg}, 0.487 \mathrm{mmol})$ and $\mathrm{K}_{2} \mathrm{CO}_{3}(292 \mathrm{mg}, 2.11 \mathrm{mmol})$ in acetone $(2 \mathrm{~mL})$ was added DMS $(0.2 \mathrm{~mL}, 2.11 \mathrm{mmol})$. The reaction mixture was stirred for $3 \mathrm{~h}$ at room temperature. The reaction was monitored by means of TLC, and the organic extract was concentrated and purified by means of column chromatography and hexane/ethyl acetate (3:1) as an eluent, whereby we obtained the compound Boc-L-Ser-OMe as a transparent gel (77 mg, 70\%). Then, the Boc-L-Ser-OMe $(34.2 \mathrm{mg}, 0.156 \mathrm{mmol})$ was dissolved in a vial containing $1 \mathrm{~mL}$ ethyl acetate (EtOAc) and benzylamine $(34.7 \mu \mathrm{L}, 0.312 \mathrm{mmol})$ and this solution was added dropwise to a solution of Celite $(100 \mathrm{mg})$ and papain $(50 \mathrm{mg})$ containing $50 \mu \mathrm{L}, \mathrm{pH} 5.5$ aqueous citric/ $\mathrm{KOH}$ solution $(3 \mathrm{M})$. The mixture was then stirred for $20 \mathrm{~h}$, and the organic phase was subsequently exacted twice with EtOAc $(1 \mathrm{~mL})$. The organic phase was dried with $\mathrm{MgSO}_{4}$, and a pale white solid was obtained $(26 \mathrm{mg}$, 56\%). Then, the abovementioned solid (1000 mg, $3.4 \mathrm{mmol}$ ) was dissolved in $0.5 \mathrm{~mL}$ DCM, followed by the addition of TFA ( $3.67 \mathrm{mg}, 5.33 \mathrm{mmol}$ ) for $1 \mathrm{~h}$ at room temperature. The reaction was monitored by means of TLC, and the organic extract was concentrated and purified by means of column chromatography. A pale-yellow solid was obtained. Then, the abovementioned solid was dissolved in a $30 \mathrm{~mL}$, $\mathrm{pH} 10.5, \mathrm{Na}_{2} \mathrm{CO}_{3} / \mathrm{NaHCO}_{3}$ buffer, followed by the addition of a $\mathrm{pH} 10.5$ aqueous $\mathrm{NaOH}$ solution $(3 \mathrm{~N})$. Methacryloyl chloride $(582.6 \mu \mathrm{L}, 8.5 \mathrm{mmol})$ was added dropwise into a flask at ice-bath temperatures within $5 \mathrm{~h}$ of mixing. The mixture was stirred with $1 \mathrm{~N} \mathrm{HCl}$ to $\mathrm{pH} 1.5$, and the organic phase was subsequently extracted with an EtOAc solution, was dehydrated with $\mathrm{MgSO}_{4}$, and was removed with a rotary evaporator. A final white solid, Methacr-L-Ser-NHBn, was obtained (70 mg, 9\%). Acr-L-Ser-NHBn, was synthesized from Boc-L-Ser-OH using similar method.
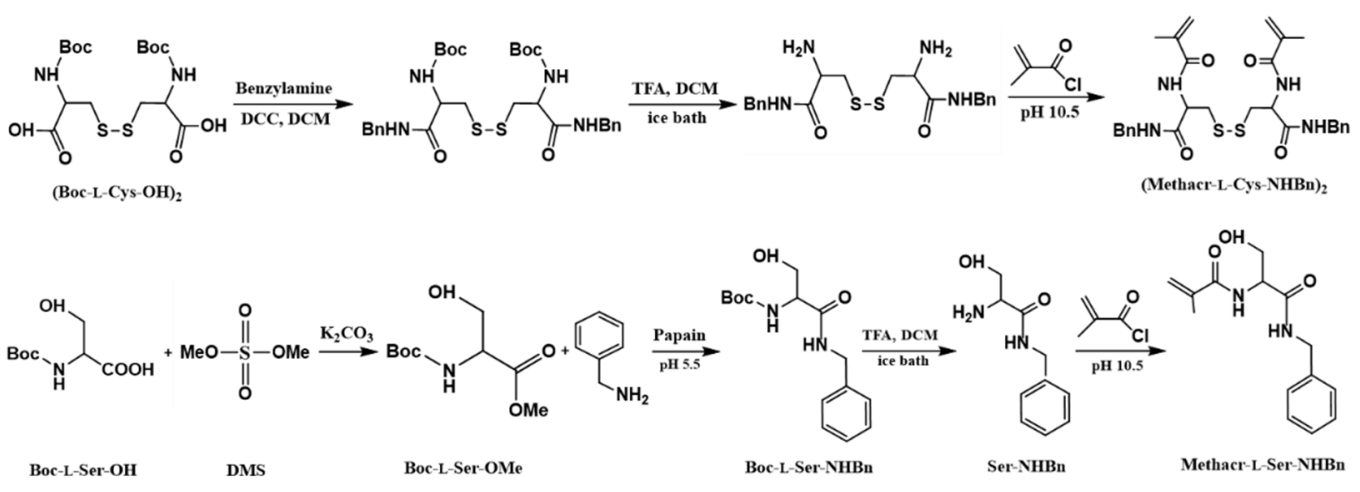

Scheme 1. The synthesis of a rigid cross-linker and a chiral functional monomer.

\subsection{Preparation of MIF-Coated QCM}

MIFs and non-imprinted films (NIFs) were synthesized by using a free radical irradiation method. Table 1 describes the compositions of the produced MIFs. NIFs were synthesized exactly the same way, with the void of a template molecule. Briefly, the QCM disks were immersed in a $54 \mu \mathrm{mol}$ solution of (Methacr-L-Cys-NHBn) $)_{2}$ in $10 \mathrm{~mL}$ ethanol (EtOH) for $72 \mathrm{~h}$ and then were rinsed exhaustively with $\mathrm{EtOH}$; then the disks were dried under vacuum. A solution of acrylamide (Am), $N$-benzylacrylamide (BA), Acr-L-Ser-NHBn, or Methacr-L-Ser-NHBn; $N, N$-ethylenebisacrylamide (EBAA) was mixed 
with template molecules in $0.3 \mathrm{~mL}$ of aqueous acetonitrile solution $(\mathrm{MeCN} / \mathrm{DI}$ water $=1: 1)$. After depositing $4 \mu \mathrm{L}$ of the aliquot on top of the (Methacr-L-Cys-NHBn)-gold electrode, the chip was placed horizontally into a $20-\mathrm{mL}$ glass vial. The vial was screwed tightly and irradiated with UV light at $350 \mathrm{~nm}$ for $6 \mathrm{~h}$. The polymer, which formed as a thin film on the gold surface, was washed with an aqueous MeCN solution, which removed the template. The QCM chip was then dried under vacuum for later use.

Table 1. Compositions of the monomer mixtures used for MIF copolymerization.

\begin{tabular}{|c|c|c|c|c|c|c|c|c|c|c|}
\hline \multicolumn{11}{|c|}{ QCM Chip } \\
\hline Formulation ( $\mu \mathrm{mol})$ & $\mathrm{MIF}_{\mathrm{BzH}}$ & MIF $_{\text {BA1 }}$ & $\mathrm{MIF}_{\mathrm{BA2}}$ & MIF FIm $_{\text {FI }}$ & MIF FTh $_{\text {FT }}$ & MIF FUL $_{F}$ & MIF $_{\text {ACT }}$ & MIF IOL $_{\text {IOL }}$ & $\mathrm{MIF}_{\mathrm{mFUL}}$ & $\mathrm{NIF}_{\mathbf{m}}$ \\
\hline \multicolumn{11}{|l|}{ Template } \\
\hline $\mathrm{BzH}$ & 55 & - & - & - & - & - & - & - & - & - \\
\hline FIm & - & 55 & 55 & 55 & - & - & - & - & - & - \\
\hline FTh & - & - & - & - & 55 & - & - & - & - & - \\
\hline FUL & - & - & - & - & - & 85 & - & - & 85 & - \\
\hline $\mathrm{ACT}$ & - & - & - & - & - & - & 55 & - & - & - \\
\hline $\mathrm{IOL}$ & - & - & - & - & - & - & - & 55 & - & - \\
\hline \multicolumn{11}{|l|}{ Monomer } \\
\hline Am & - & 55 & 55 & 55 & 55 & 55 & 55 & 55 & 55 & 55 \\
\hline $\mathrm{BA}$ & 165 & 55 & 55 & - & - & - & - & - & - & 55 \\
\hline Acr-L-Ser-NHBn & - & - & - & 55 & 55 & 55 & 27.5 & 55 & - & - \\
\hline 4-VIM & - & - & - & - & - & - & 27.5 & - & - & - \\
\hline Methacr-L-Ser-NHBn & - & - & - & - & - & - & - & - & 55 & - \\
\hline Cross-linker & & & & & & & & & & \\
\hline (Methacr-L-Cys-NHBn) ${ }_{2}$ & 54 & 54 & 54 & 54 & 54 & 54 & 54 & 54 & 54 & 54 \\
\hline EBAA & 165 & 110 & 220 & 110 & 110 & 110 & 110 & 110 & 110 & 110 \\
\hline Substrate & FUL & FUL & FUL & FUL & FUL & FUL & $\mathrm{ACF}$ & FOL & FUL & FUL \\
\hline
\end{tabular}

BzH: Benzylaldehyde; FIm: 2-formylimidazole; FTh: 2-formylthiazole; FUL: 2-furaldehyde; ACT: 2-acetylthiazole; IOL: imidazole-2methanol; Am: acrylamide; BA: N-benzylacrylamide; 4-VIM: 4-vinyl-imidazole; EBAA: ethylenebisacrylamide; ACF: 2-acetylfuran; FOL: 2-furfuryl alcohol; mFUL: Imprinted film by Methacr-L-Ser-NHBn; NIFm: nonimprinted film by Methacr-L-Ser-NHBn.

\subsection{Binding Measurement}

All adsorption experiments were performed using a setup comprised of the flow-injection system, equipped with an HPLC pump (model L7110, Hitachi, flow rate $0.3 \mathrm{~mL} / \mathrm{min}$ ), a home-built flow cell, a sample injection valve (model 1106, OMNIFIT, Toms River, NJ, USA), a home-built oscillation circuit (including an oscillator and a frequency counter), and a personal computer. The polymer-coated QCM was fixed between two O-rings and inserted into the flow cell. Only one side of the QCM was in contact with the liquid. A mixture solution of heptane/acetone $(95 / 5, v / v)$ was used for circulating, washing, and testing. To equilibrate the newly imprinted chips quickly, $100 \mu \mathrm{L}$ of heptane/IPA $(95 / 5, v / v)$ solution were taken in distilled water and were injected into the flow cell during circulation.

\subsection{Measurement of Furanic Compounds in Insulating Oil}

The prepared MIF-QCM sensor was employed to detect furanic compounds in insulating oil and, thus, to verify the performance and feasibility of the developed sensor in real samples. The insulating oil (containing $300 \mu \mathrm{g} / \mathrm{mL}$ FUL) was diluted to a certain concentration in an organic solvent (3:7) by using organic solvent (heptane/acetone (95:5, $v / v)$ ) for further analysis. The resultant solution $100 \mu \mathrm{L}$ (containing $90 \mu \mathrm{g} / \mathrm{mL}$ FUL) was taken to inject into the MIF-QCM sensor system.

\section{Results and Discussions}

To investigate the structure-based design in targeting furanic compounds (Figure 1a) using MIF-QCM, six model templates (Figure 1b) were selected with which we tested the affinity and specificity of furanic compounds. These selections were driven by the 
amphiphilic hydrophobic/hydrophilic character of the molecules, owing to the presence of an aromatic ring and a carbonyl group.

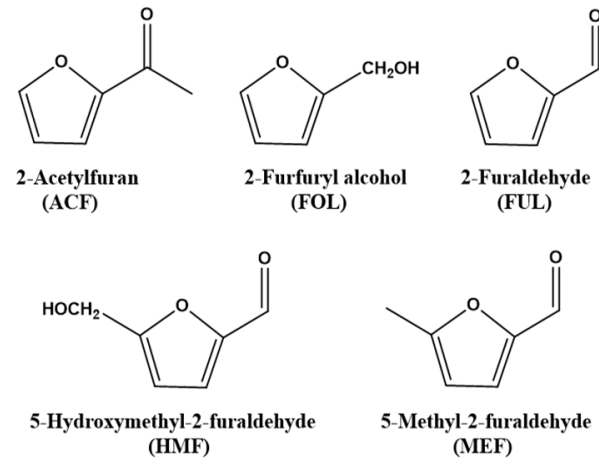

(a)

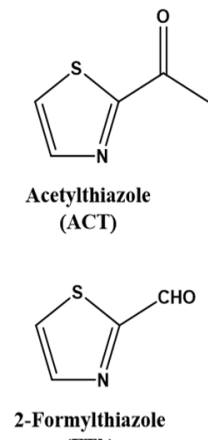

(FTh)

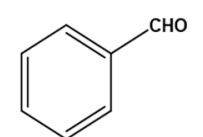

Benzylaldehyde (BzH)

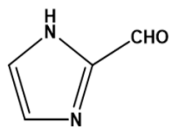

2-Formylimidazole (FIm)

(b)

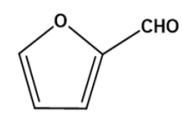

2-Furaldehyde (FUL)

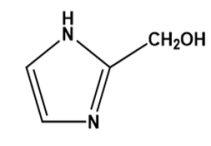

Imidazole-2-methanol (IOL)

Figure 1. (a) Five furanic compounds and (b) six model templates used in this study.

In general, an aromatic group is a ring-shaped, planar structure with $\pi$ bonds whose resonance possibilities play pivotal roles in stabilizing molecular structures [27]. Besides the hydrophilic and hydrophobic interactions, intermolecular features like hydrogen bonding and $\pi$-type interactions are the parameters with an important effect on molecular imprinting efficiency, which depends on the formation of specific cavities inside the film network. Given the recognition properties, MIFs could be used for the sensing of low-molecular weight compounds such as furans.

\subsection{Synthesis and Properties of (Methacr-L-Cys-NHBn) $)_{2}$ and (Methacr-L-Ser-NHBn)}

For the current study, a neutral cross-linker with two chiral centers and a disulfide bond (Methacr-L-Cys-NHBn) ${ }_{2}$ were synthesized with two methacryloyl groups for MIF formation. The synthesis was performed similar to our previously reported procedure with a total yield of $18 \%$ from ((Boc-L-Cys) 2 ) [8,28]. As for the synthesis of the hydrophilic functional monomer, (Methacr-L-Ser-NHBn), the process was straightforward, with $9 \%$ from (Boc-L-Ser-OH). The Supplementary Materials presents details regarding ${ }^{1} \mathrm{H}-\mathrm{NMR}$, ${ }^{13} \mathrm{C}-\mathrm{NMR}$, and mass spectra of (Methacr-L-Cys-NHBn) ${ }_{2}$ and (Methacr-L-Ser-NHBn).

The QCM employed in this work consisted of a disk of crystalline quartz with gold electrodes on the upper and lower surfaces. Although protic solvents such as alcohols and water are suitable for free-radical polymerization, the use of water in both the polymersynthesis step and the recognition step has evident advantages over organic systems. However, because the poor solubility of the template and monomer in the aqueous solution, our solvent of choice was a water/acetonitrile mixture. Clear solutions were obtained, indicating that miscible interactions had been established between the functional monomers, the cross-linkers, and the template species.

The disulfide functional group of (Methacr-L-Cys-NHBn) $)_{2}$ fabricated a self-assembled monolayer (SAM), which enabled (Methacr-L-Cys-NHBn) 2 to attach to the gold chip; whose high affinity for the surfaces makes it more tightly than (Acr-L-Cys-NHBn) ${ }_{2}$ [8]. Afterward, monomers and cross-linkers were irradiated in the presence of template to copolymerize with (Methacr-L-Cys-NHBn) ${ }_{2}$-Au complex. In addition, the benzylamide groups of (Methacr-L-Cys-NHBn) 2 also help to prevent displacement of the polymer because of the self-assembly of either the benzyl group of benzylacrylamide or the template to a hydrophobic layer. All the monomers and cross-linkers were thus attached to the chip surface so that, after copolymerization, the formulation of MIF could take place in an organized manner. 


\subsection{Preparation of MIFs}

To verify our hypothesis concerning structural-based design in binding and selectivity, we synthesized various kinds of MIFs by changing the functional monomers (Am, BA, 4-VIM, Acr-L-Ser-NHBn, Methacr-L-Ser-NHBn, and EBAA were alternatively used). As for the cross-linkers serving the polymer film network generation, we chose EBAA and (Methacr-L-Cys-NHBn) 2 (see Table 1). The selected solvents were acetonitrile, methanol, and water, or their mixtures. We tested diverse types of interactions between the template molecule and the functional monomers. The effect of structural interactions on molecular imprinting efficiency for the determination of furanic compounds present was also examined.

\subsection{Binding Studies for FUL Determination}

\subsubsection{Analysis of Molecular-Structure Similarity Using Pseudo-Template}

Because furanic compounds could be destroyed at high temperatures or high energy conditions, $\mathrm{BzH}$, a planar electrophile with an aromatic skeleton, was chosen as a pseudotemplate to construct $\mathrm{MIF}_{\mathrm{BzH}}-\mathrm{QCM}$ for detecting FUL. Due to its hydrophobic attraction from $\pi-\pi$ interactions, the hydrophobicity between the imprinting template $\mathrm{BzH}$ and the monomers may be very important. Thus, we increased the amounts of BA to $165 \mu \mathrm{mol}$ to form a polymerization complex, and did so by irradiation with BA and EBAA at a molar ratio of 1:1, and we placed the template in a water/acetonitrile mixture with a water-to-acetonitrile ratio of 1:1. A thin film $\mathrm{MIF}_{\mathrm{BzH}}$ was formed on the QCM chip, and we washed it with an organic solvent (heptane/IPA $=95: 5, v / v$ ), thereby removing $70 \%$ to $80 \%$ of the template. Contrary to our expectation, the polymer matrices that developed during the polymerization were not sufficient to provide enough selectivity for FUL (Figure 2).

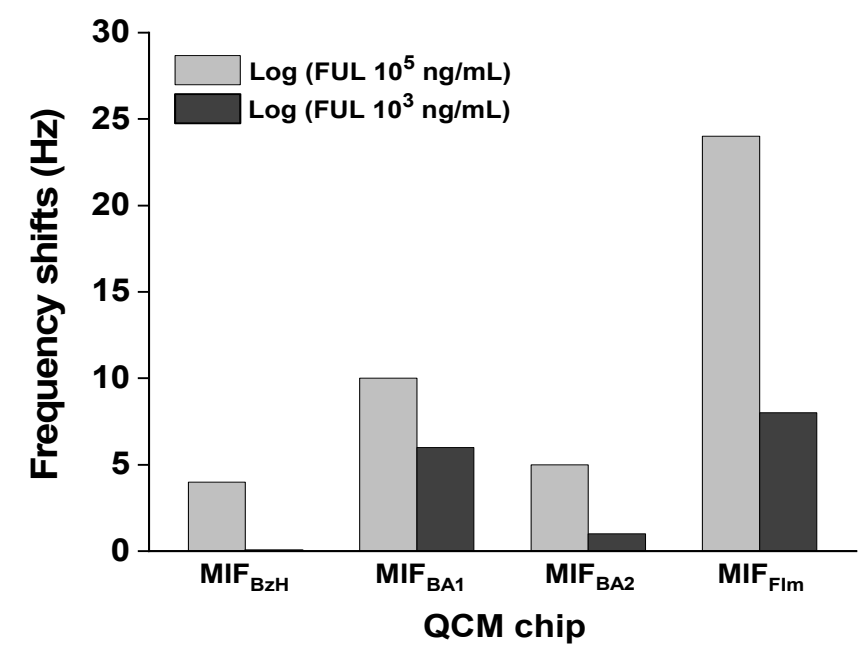

Figure 2. The frequency shifts obtained on FUL binding by constructing MIFs using pseudo-template BzH or FIm (MIF BA1 $_{1}$ MIF $_{\mathrm{BA} 2}$, and $\left.\mathrm{MIF}_{\mathrm{FIm}}\right)$. The compositions of MIFs are shown in Table 2. A mixed solution of heptane/acetone $(95 / 5, v / v)$ was used for circulating, washing, and testing. MIF $_{\mathrm{FIm}}$ : Acr-L-Ser-NHBn, Am, and EBAA (at a molar ratio of 1:1:2). BzH = benzylaldehyde; FIm = 2-formylimidazole; FUL = 2-furaldehyde.

Thus, a polar pseudo-template FIm was introduced in a water/acetonitrile solution (water-to-acetonitrile ratio of 1:1) and irradiated with Am, BA, EBAA (at a ratio of 1:1:2 and 1:1:4), to form $\mathrm{MIF}_{\mathrm{BA} 1}$ and $\mathrm{MIF}_{\mathrm{BA} 2}$, respectively. Once polymerization was completed and the pseudo-template was removed by washing, the polymer film matrices that had developed during the polymerization were still not sufficient to provide good selectivity toward FUL substrate (Figure 2). The EBAA concentration at a molar ratio of 4:1 relative to the pseudo-template was too high. This is due to uncorrelated relationship between the polymerization degree and the template molecules. 
Table 2. Comparison of various MIF-QCM assays in different analytes.

\begin{tabular}{ccccc}
\hline QCM Chip & Substrate & $\begin{array}{c}\text { Molecular Weight } \\
\text { (Da) }\end{array}$ & $\begin{array}{c}\text { Detection Limit } \\
\text { (ng/mL) }\end{array}$ & $\begin{array}{c}\mathbf{K}_{\mathbf{d}} \\
(\mathbf{n M})\end{array}$ \\
\hline MIF $_{\text {BzH }}$ & FUL & 96 & $1 \times 10^{5}$ & $2.22 \times 10^{6}$ \\
MIF FIm $_{\text {MIF }}$ & FUL & 96 & 1000 & $2.12 \times 10^{4}$ \\
MIF $_{\text {FUL }}$ & FUL & 96 & 100 & $1.87 \times 10^{3}$ \\
MIF & FUL & 96 & 10 & 170 \\
MIF & ACF & 110 & 100 & $1.51 \times 10^{4}$ \\
L-Tryptophan [9] & FOL & 98 & $1.80 \times 10^{3}$ & $4.35 \times 10^{4}$ \\
Nandrolone [10] & Nandrolone & 204 & 50 & $1.82 \times 10^{5}$ \\
L-Glutamic acid [29] & L-Glutamic acid & 274 & $1.47 \times 10^{3}$ & 8.12 \\
Hexachlorobenzene [30] & Hexachlorobenzene & 147 & $2.80 \times 10^{-4}$ & $6.86 \times 10^{5}$ \\
\hline
\end{tabular}

BzH: benzaldehyde; FIm: 2-formylimidazole; FTh: 2-formylthiazole; FUL: 2-furaldehyde FUL: 2-furaldehyde; ACT: 2-acetylthiazole; IOL: imidazole-2-methanol; ACF: 2-acetylfuran; FOL: 2-furfuryl alcohol.

Next, Acr-L-Ser-NHBn was utilized as a chiral monomer to construct MIF $\mathrm{MIm}_{\text {on }}$ o QCM chip with Am and EBAA at a molar ratio of 1:1:2 to provide a higher polarity (Table 1). The corresponding frequency changes for $10^{5} \mathrm{ng} / \mathrm{mL}$ of FUL solution and for $10^{3} \mathrm{ng} / \mathrm{mL}$ of FUL solution were $24 \mathrm{~Hz}$ and $8 \mathrm{~Hz}$, respectively. Without the hydrophilic monomer Acr-L-Ser-NHBn, the polymer matrices that developed during the polymerization would not have been sufficient to improve the hydrogen bonding interaction and the recognition ability of MIF $\mathrm{FIm}_{\text {tow }}$ tow FUL. In compare to $\mathrm{MIF}_{\mathrm{BzH}}, \mathrm{MIF}_{\mathrm{BA} 1}$, and $\mathrm{MIF}_{\mathrm{BA} 2}$ (Figure 2), the resulting imprinting performance of $\mathrm{MIF}_{\mathrm{FIm}}$ was successful, indicating the selective sites for binding FUL have been formed on $\mathrm{MIF}_{\mathrm{FIm}}$.

\subsubsection{FIm, FTh, and FUL Templates for the Determination of FUL}

To demonstrate the effects of the pseudo-template and their mother substrate on the MIF, FIm, FTh, and FUL were used as templates to form the thin films, respectively. The amount of the FUL template was increased to $85 \mu \mathrm{mol}$, because FUL is a vulnerable compound and could be destroyed during the process.

The mass changes were examined with various FUL solutions $(100 \mathrm{ng} / \mathrm{mL}$ to $100 \mu \mathrm{g} / \mathrm{mL}$ ) using $\mathrm{MIF}_{\mathrm{FTh}}-\mathrm{QCM}$ sensor; likewise, various FUL solutions $(10 \mathrm{ng} / \mathrm{mL}$ to $500 \mu \mathrm{g} / \mathrm{mL})$ using $\mathrm{MIF}_{\mathrm{FUL}}-\mathrm{QCM}$ sensor (Figure 3a). Indicating the importance of cross-linker grafted interactions between the template and Acr-L-Ser-NHBn were very important in relation to the $\mathrm{MIF}_{\mathrm{FIm}}-\mathrm{QCM}$ sensor. The detection limit of the developed $\mathrm{MIF}_{\mathrm{FTh}}-\mathrm{QCM}$ sensor can reach $100 \mathrm{ng} / \mathrm{mL}$, which is better than $\mathrm{MIF}_{\mathrm{FIm}}-\mathrm{QCM}$ sensor. Of note is our finding that the $\mathrm{MIF}_{\mathrm{FUL}}-\mathrm{QCM}$ sensor in the target FUL substrate was more sensitive than the other MIF-QCM sensors, reaching a level of sensitivity equivalent to $10 \mathrm{ng} / \mathrm{mL}$.

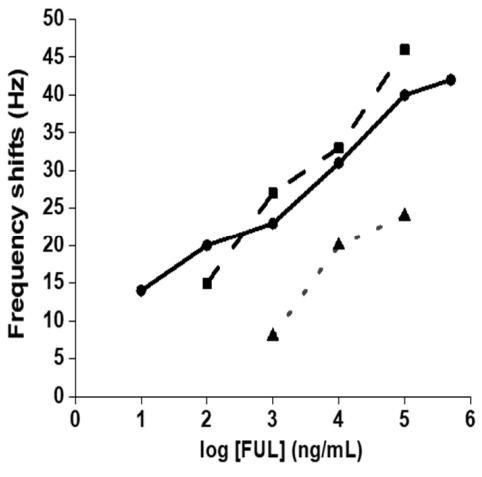

(a)

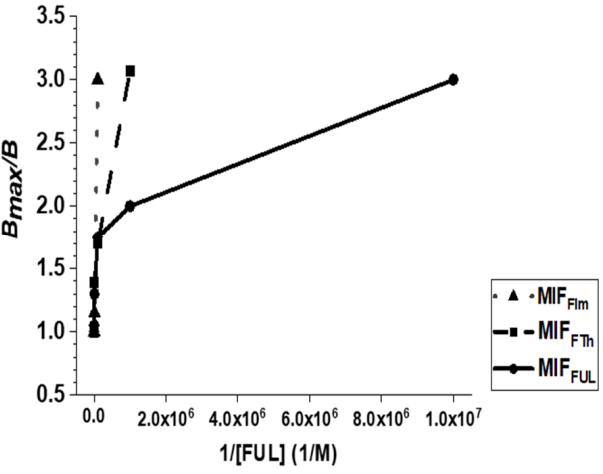

(b)

Figure 3. (a) The frequency-shift results and (b) the binding results for the FIm, FTh, and FUL templates, with a focus on the FUL binding to MIFs, as obtained from the MIF-QCM sensor. A mixed solution of heptane/acetone $(95 / 5, v / v)$ was used for circulating, washing, and testing. FIm = 2-formylimidazole; FTh = 2-formylthiazole; FUL = 2-furaldehyde. 
Binding studies were then performed to evaluate the maximal capacities of the MIFQCM chips and the chips' binding affinities. Relative to the FUL substrate itself, the $\mathrm{K}_{\mathrm{d}}$ value of our target $\mathrm{MIF}_{\mathrm{FUL}}-\mathrm{QCM}$ chip was calculated to be $170 \mathrm{nM}$; the $\mathrm{K}_{\mathrm{d}}$ value of the $\mathrm{MIF}_{\mathrm{FTh}}-\mathrm{QCM}$ chip was $1.87 \times 10^{3} \mathrm{nM}$; and the $\mathrm{K}_{\mathrm{d}}$ value of the $\mathrm{MIF}_{\mathrm{FIm}}-\mathrm{QCM}$ chip was $2.12 \times 10^{4} \mathrm{nM}$ (Figure $3 \mathrm{~b}$ ). These results strongly suggest that the MIF FUL-QCM chip possesses the most efficient means for discriminating among the targets.

\subsubsection{The Use of $\mathrm{MIF}_{\mathrm{ACT}}$ and $\mathrm{MIF}_{\mathrm{IOL}}$ Chips for the Detection of ACF and FOL}

The above results indicate that the $\mathrm{MIF}_{\mathrm{FUL}}-\mathrm{QCM}$ chip demonstrated better binding ability than was the case with the $\mathrm{MIF}_{\mathrm{BA} 1}-\mathrm{QCM}$ chip and the $\mathrm{MIF}_{\mathrm{FTh}}-\mathrm{QCM}$ chip. We next used the molar ratio of the monomer mixture to detect two similar types of furanic compounds: 2-acetylfuran (ACF) and 2-furfuryl alcohol (FOL). The pseudo-templates $\mathrm{ACT}$ and IOL and the aprotic monomers were then used to form corresponding MIF by means of irradiation with Am, Acr-L-Ser-NHBn, or 4-VIM (at a molar ratio of 1:1:1 or 1:1:0, respectively), and the templates were placed in a water/MeCN solution (at a 1:1 ratio, $v / v$ ) according to the same process that we had used for $\mathrm{MIF}_{\mathrm{FUL}}-\mathrm{QCM}$ sensor. The mass change for the $\mathrm{MIF}_{\mathrm{ACT}}$ in various ACF aqueous solutions $(100 \mathrm{ng} / \mathrm{mL}$ to $100 \mu \mathrm{g} / \mathrm{mL})$ were observed on $\mathrm{MIF}_{\mathrm{ACT}}-\mathrm{QCM}$ sensor; similarly, so were $\mathrm{MIF}_{\mathrm{IOL}}$ in various FOL aqueous solutions (1000 ng/mL to $100 \mu \mathrm{g} / \mathrm{mL}$ ) on $\mathrm{MIF}_{\mathrm{IOL}}-\mathrm{QCM}$ sensor (Figure 4).

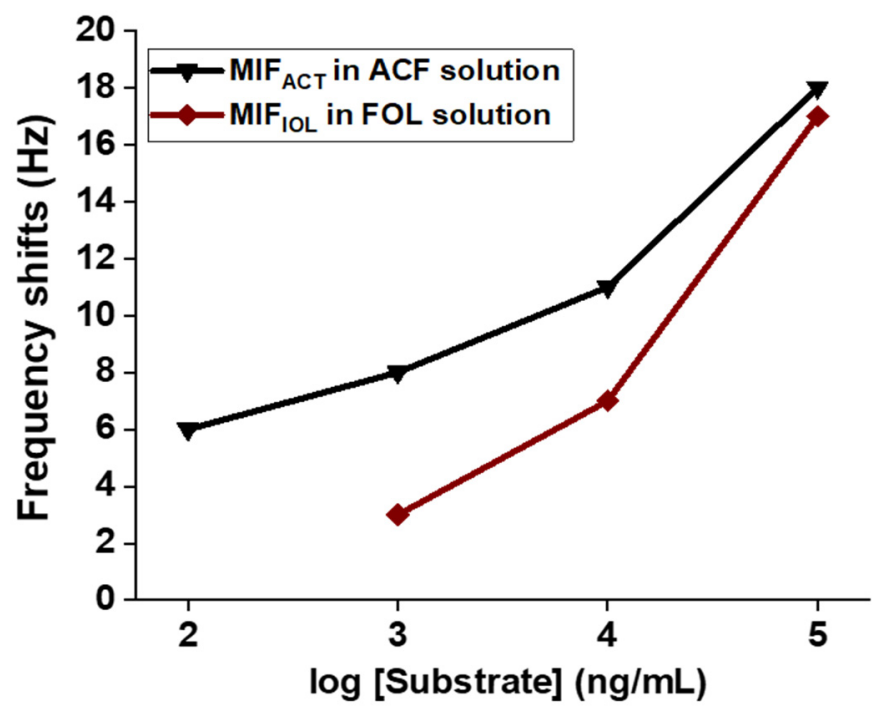

Figure 4. The frequency-shift results for the $\mathrm{MIF}_{\mathrm{ACT}}$ and $\mathrm{MIF}_{\mathrm{IOL}}$ templates, with a focus on the ACT and IOL binding to ACF and FOL, respectively, as obtained from MIF-QCM sensor. A mixed solution of heptane/acetone $(95 / 5, v / v)$ was used for circulating, washing, and testing. ACT = acetylthiazole; $\mathrm{IOL}=$ Imidazole-2-methanol; ACF = 2-acetylfuran; FOL = 2-furfuryl alcohol.

The detection limitation of the $\mathrm{MIF}_{\mathrm{ACT}}-\mathrm{QCM}$ chip reached $100 \mathrm{ng} / \mathrm{mL}$, with a $\mathrm{K}_{\mathrm{d}}$ value of $1.51 \times 10^{4} \mathrm{nM}$; the $\mathrm{MIF}_{\mathrm{IOL}}-\mathrm{QCM}$ chip reached only $1000 \mathrm{ng} / \mathrm{mL}$, with a $\mathrm{K}_{\mathrm{d}}$ value of $4.35 \times 10^{4} \mathrm{nM}$. The results suggest that the target-binding ability of the $\mathrm{MIF}_{\mathrm{ACT}}-\mathrm{QCM}$ chip is superior to that of the $\mathrm{MIF}_{\mathrm{IOL}}-\mathrm{QCM}$ chip.

\subsubsection{Hydrophobic Functional Monomer (Methacr-L-Ser-NHBn) for Determination of FUL}

To increase the film hydrophobicity for binding efficacy, a more hydrophobic monomer (Methacr-L-Ser-NHBn) was used by irradiating with Am and EBAA (at a ratio of 1:1:2) according to the same process that we had used abovementioned. The mass change was observed for the $\mathrm{MIF}_{\mathrm{mFUL}}$ (i.e., the imprinted film with Methacr-L-Ser-NHBn) in various FUL aqueous solutions ( $1000 \mathrm{ng} / \mathrm{mL}$ to $100 \mu \mathrm{g} / \mathrm{mL}$ ) on $\mathrm{MIF}_{\mathrm{mFUL}}-\mathrm{QCM}$ sensor. The target-binding ability of the $\mathrm{MIF}_{\mathrm{mFUL}}-\mathrm{QCM}$ sensor was $13 \%$ higher than the targetbinding ability of the $\mathrm{MIF}_{\mathrm{FUL}}-\mathrm{QCM}$ sensor in a FUL solution having a concentration 
of $10^{5} \mathrm{ng} / \mathrm{mL}$. In contrast, the corresponding values for the reference-that is, the nonimprinted film $\left(\mathrm{NIF}_{\mathrm{m}}\right)$-did not undergo significant changes regarding its target-binding ability. In Figure 5, $\mathrm{MIF}_{\mathrm{mFUL}}$ regression analyses on the relevant data set, and the results show that the correlation among the different concentrations of the FUL substrate was apparently linear $\left(R^{2}=0.964\right)$, suggesting that the target-binding ability generated in the $\mathrm{MIF}_{\mathrm{mFUL}}$ was more efficient than the corresponding ability generated in the $\mathrm{MIF}_{\mathrm{FUL}}$.

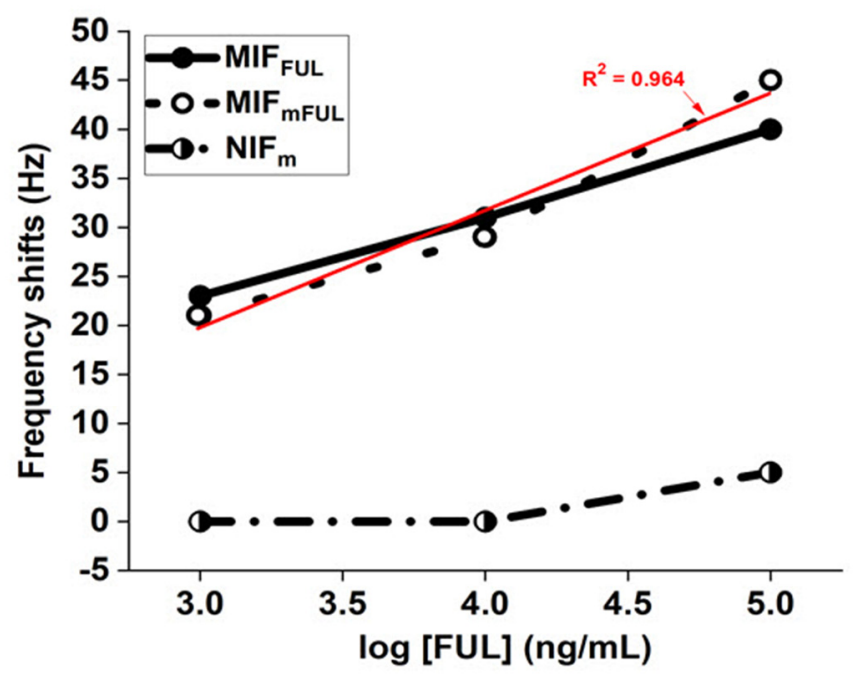

Figure 5. The frequency-shift results for the FUL template, with a focus on the FUL binding to the $\mathrm{MIF}_{\mathrm{mFUL}}$ and $\mathrm{MIF}_{\mathrm{FUL}}$, as obtained from the $\mathrm{MIF}_{\mathrm{mFUL}}-\mathrm{QCM}$ and $\mathrm{MIF}_{\mathrm{FUL}}-\mathrm{QCM}$ sensor. A mixed solution of heptane/acetone $(95 / 5, v / v)$ was used for circulating, washing, and testing. FUL = 2-furaldehyde; MIFm = imprinted film with Methacr-L-Ser-NHBn; NIFm = non-imprinted film with Methacr-L-Ser-NHBn.

\subsection{Comparison of the MIF-QCM Chip}

Basically, the molecular weight of furanic compounds is around 100 Dalton which is smaller than the compounds reported in literature $[9,10,29,30]$. In this respect, the $K_{d}$ value of FUL assay will be expected to higher than those reported. However, $\mathrm{MIF}_{\mathrm{FUL}}$ shows a binding affinity toward FUL as $170 \mathrm{nM}$, which is lower than others except for nandrolone [10] and hexachlorobenzene [30] (Table 2).

MIF-QCM analytical methods are based exclusively on the binding affinity of MIF toward substrate according to its molecular weight $[9,10,29,30]$. The detection limit of MIF (less than $50 \mathrm{ng} / \mathrm{mL}$ ) is usually in respect to the substrate's functionality. The detection limit of $\mathrm{MIF}_{\mathrm{FUL}}$ reached $10 \mathrm{ng} / \mathrm{mL}$, which is only higher than hexachlorobenzene [30].

\subsection{Determination of Furanic Compounds in Insulating Oil}

Previously, molecularly imprinted polymers fabricated on QCM sensors for monitoring automobile oil have been reported [31]. The concentration of furanic compounds is a good indicator to check the durability of an oil-immersed self-cooling high voltage transformer [32,33]. As our MIF-QCM chip for detecting furanic compounds in organic solvent demonstrated low detection limits, this novel detection system was then applied to screen a partial library of furanic compounds in organic solvent. The five furanic compounds (FUL, FOL, ACF, HMF, and MEF) were tested using $\mathrm{MIF}_{\mathrm{FUL}}-\mathrm{QCM}$ sensor in organic solvent (Figure 6, gray bar). Among them, FUL was the principal compound observed, with a frequency of $40 \mathrm{~Hz}$. 


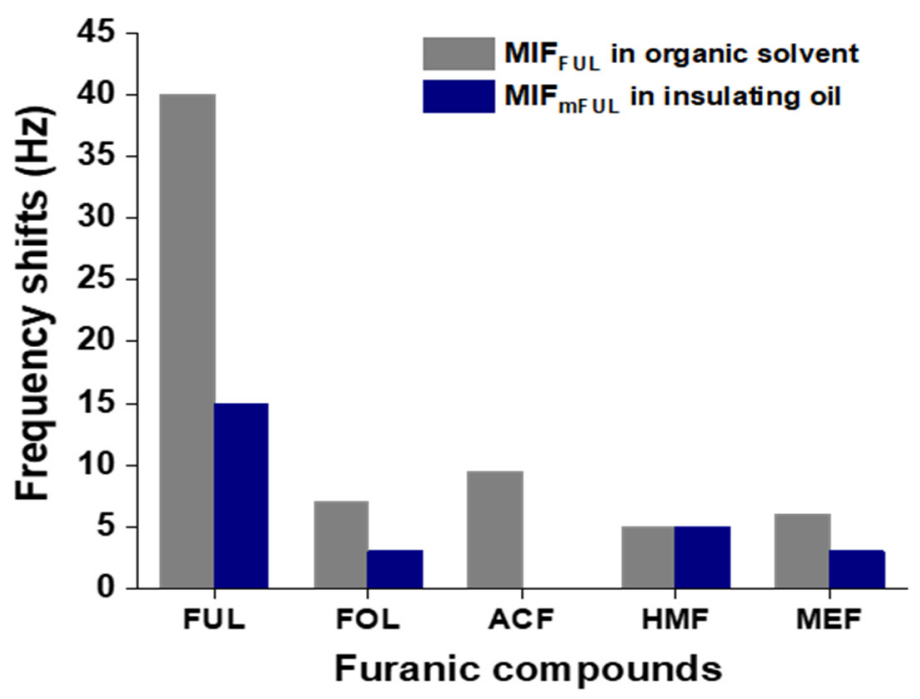

Figure 6. The frequency-shift results for furanic compounds by comparing MIFm-QCM sensors with insulating oil and MIF-QCM sensors in organic solvents. A mixture solution of heptane/acetone $(95 / 5, v / v)$ was used for circulating in MIF-QCM sensors. FUL = 2-furaldehyde; FOL = 2-furfuryl alcohol; ACF = 2-acetylfuran; HMF = 5-hydroxymethyl-2-furaldehyde; MEF = 5-methyl-2-furaldehyde; $\mathrm{MIF}_{\mathrm{m}}=$ imprinted film with Methacr-L-Ser-NHBn.

However, it will be important to overcome viscosity problem for testing furanic compounds directly in insulating oil samples. Therefore, operation of $\mathrm{MIF}_{\mathrm{mFUL}}-\mathrm{QCM}$ sensor for the tested samples was carried out. The furans that can be recognized by MIFmFUL-QCM sensor in insulating oil were FUL, FOL, HMF, and MEF (Figure 6, blue bar). Among them, only FUL was easily detected. Lower contents of FOL, HMF, and MEF were detectable in these systems. Nevertheless, the correlation of furanic compounds has not been justified by their instability and long aging time. The lack of other related compounds to serve as pseudo-template has only been partially revealed in this studied.

\section{Conclusions}

We have prepared furan structure-specific films as molecular recognition sites for particular furanic compounds. Separation and quantitation of these furanic compounds were successfully performed by using a modified MIF-QCM sensor. When prepared according to this method, our artificial structure-based design is conceptually attractive insofar as it nicely complements the binding modularity of natural counterparts. The advantages of MIFs include the ability to perform in harsh conditions such as at organic solvent flow systems and high viscosity and hydrophobic systems. In spite of the matrix complexity, no sample pretreatment was required, apart from dilution and filtration. In actual samples, FUL, FOL, HMF, and MEF were detected. Sensitivity can reach $10 \mathrm{ng} / \mathrm{mL}$. The MIF-QCM sensor may prove useful for preparing materials that recognize substances or other compounds for which the structural information needed for rational ligand design is lacking. Likewise, if a natural receptor is poorly characterized or hard to separate, artificially prepared mimics may serve as a useful complement.

Supplementary Materials: The following are available online at https:/ / www.mdpi.com/article/10 .3390 / chemosensors9120338/s1, Figure S1: ${ }^{1}$ H-NMR spectrum of (Methacr-L-Cys-NHBn) 2 , Figure S2: ${ }^{13}$ C-NMR spectrum of (Methacr-L-Cys-NHBn) 2 , Figure S3: Mass spectrum of (Methacr-L-CysNHBn) $)_{2}$, Figure S4: IR spectrum of (Methacr-L-Cys-NHBn) 2 , Figure S5: ${ }^{1} \mathrm{H}-\mathrm{NMR}$ spectrum of Methacr-L-Ser-NHBn, Figure S6: ${ }^{13}$ C-NMR spectrum of Methacr-L-Ser-NHBn, Figure S7: Mass spectrum of Methacr-L-Ser-NHBn, Figure S8: IR spectrum of Methacr-L-Ser-NHBn. 
Author Contributions: The listed authors contributed to this work as described in the following: W.-L.L., Methodology, Resources, Formal Analysis; C.-Y.L., Investigation, Formal Analysis, WritingOriginal draft preparation; D.-F.T., Conceptualization, Data curation, Supervision, Writing-Reviewing and Editing. All authors have read and agreed to the published version of the manuscript.

Funding: Ministry of Science and Technology (MOST), Taiwan (109-2221-E-182-008-MY3), and the Chang Gung Memorial Hospital, Taiwan (CMRPD1K0101).

Institutional Review Board Statement: Not applicable.

Informed Consent Statement: Not applicable.

Data Availability Statement: Not applicable.

Acknowledgments: The authors also thank the Microscopy Center at Chang Gung University for technical assistance.

Conflicts of Interest: The authors declare no conflict of interest.

\section{References}

1. Amaral, M.; Kokh, D.B.; Bomke, J.; Wegener, A.; Buchstaller, H.P.; Eggenweiler, H.M.; Matias, P.; Sirrenberg, C.; Wade, R.C.; Frech, M. Protein conformational flexibility modulates kinetics and thermodynamics of drug binding. Nat. Commun. 2017, 8, 2276. [CrossRef]

2. Rebek, J. Introduction to the molecular recognition and self-assembly special feature. Proc. Natl. Acad. Sci. USA 2009, 106, 10423-10424. [CrossRef] [PubMed]

3. Kim, H.; Spivak, D.A. New insight into modeling non-covalently imprinted polymers. J. Am. Chem. Soc. 2003, 125, 11269-11275. [CrossRef]

4. Emir Diltemiz, S.; Keçili, R.; Ersöz, A.; Say, R. Molecular imprinting technology in quartz crystal microbalance (QCM) sensors. Sensors 2017, 17, 454. [CrossRef] [PubMed]

5. Chen, S.; Dong, L.; Yan, M.; Dai, Z.; Sun, C.; Li, X. Rapid and sensitive biomarker detection using molecular imprinting polymer hydrogel and surface-enhanced Raman scattering. R. Soc. Open Sci. 2018, 5, 171488. [CrossRef]

6. Luo, K.; Chen, H.; Zhou, Q.; Yan, Z.; Su, Z.; Li, K. A sensitive and visual molecularly imprinted fluorescent sensor incorporating $\mathrm{CaF}(2)$ quantum dots and $\beta$-cyclodextrins for 5-hydroxymethylfurfural detection. Anal. Chim. Acta 2020, 1124, 113-120. [CrossRef] [PubMed]

7. Saylan, Y.; Erdem, Ö.; Inci, F.; Denizli, A. Advances in biomimetic systems for molecular recognition and biosensing. Biomimetics 2020, 5, 20. [CrossRef]

8. Lin, C.Y.; Tai, D.F.; Wu, T.Z. Discrimination of peptides by using a molecularly imprinted piezoelectric biosensor. Chem. Eur. J. 2003, 9, 5107-5110. [CrossRef]

9. Liu, F.; Liu, X.; Ng, S.-C.; Chan, H.S.-O. Enantioselective molecular imprinting polymer coated QCM for the recognition of 1-tryptophan. Sens. Actuators B Chem. 2006, 113, 234-240. [CrossRef]

10. Percival, C.J.; Stanley, S.; Braithwaite, A.; Newton, M.I.; McHale, G. Molecular imprinted polymer coated QCM for the detection of nandrolone. Analyst 2002, 127, 1024-1026. [CrossRef]

11. Unger, C.; Lieberzeit, P.A. Molecularly imprinted thin film surfaces in sensing: Chances and challenges. React. Funct. Polym. 2021, 161, 104855. [CrossRef]

12. Derz, W.; Fleischmann, M.; Elsinghorst, P.W. Guiding molecularly imprinted polymer design by pharmacophore modeling. Molecules 2021, 26, 5101. [CrossRef]

13. Refaat, D.; Aggour, M.G.; Farghali, A.A.; Mahajan, R.; Wiklander, J.G.; Nicholls, I.A.; Piletsky, S.A. Strategies for molecular imprinting and the evolution of MIP nanoparticles as plastic antibodies-synthesis and applications. Int. J. Mol. Sci. 2019, $20,6304$. [CrossRef]

14. Vasapollo, G.; Sole, R.D.; Mergola, L.; Lazzoi, M.R.; Scardino, A.; Scorrano, S.; Mele, G. Molecularly imprinted polymers: Present and future prospective. Int. J. Mol. Sci. 2011, 12, 5908-5945. [CrossRef] [PubMed]

15. Pesavento, M.; Merli, D.; Biesuz, R.; Alberti, G.; Marchetti, S.; Milanese, C. A MIP-based low-cost electrochemical sensor for 2-furaldehyde detection in beverages. Anal. Chim. Acta 2021, 1142, 201-210. [CrossRef] [PubMed]

16. Pesavento, M.; Zeni, L.; De Maria, L.; Alberti, G.; Cennamo, N. SPR-optical fiber-molecularly imprinted polymer sensor for the detection of furfural in wine. Biosensors 2021, 11, 72. [CrossRef] [PubMed]

17. Cennamo, N.; De Maria, L.; D'Agostino, G.; Zeni, L.; Pesavento, M. Monitoring of low levels of furfural in power transformer oil with a sensor system based on a POF-MIP platform. Sensors 2015, 15, 8499-8511. [CrossRef]

18. Unsworth, J.; Mitchell, F. Degradation of electrical insulating paper monitored with high performance liquid chromatography. IEEE Transs Electr. Insul. 1990, 25, 737-746. [CrossRef]

19. Hashemi-Moghaddam, H.; Ahmadifard, M. Novel molecularly-imprinted solid-phase microextraction fiber coupled with gas chromatography for analysis of furan. Talanta 2016, 150, 148-154. [CrossRef] 
20. Athikomrattanakul, U.; Katterle, M.; Gajovic-Eichelmann, N.; Scheller, F.W. Development of molecularly imprinted polymers for the binding of nitrofurantoin. Biosens. Bioelectron. 2009, 25, 82-87. [CrossRef]

21. Mu, L.N.; Wang, X.H.; Zhao, L.; Huang, Y.P.; Liu, Z.S. Low cross-linked molecularly imprinted monolithic column prepared in molecular crowding conditions. J. Chromatogr. A 2011, 1218, 9236-9243. [CrossRef] [PubMed]

22. Spivak, D.A. Optimization, evaluation, and characterization of molecularly imprinted polymers. Adv. Drug Deliv. Rev. 2005, 57, 1779-1794. [CrossRef] [PubMed]

23. Steuber, H.; Zentgraf, M.; La Motta, C.; Sartini, S.; Heine, A.; Klebe, G. Evidence for a novel binding site conformer of aldose reductase in ligand-bound state. J. Mol. Biol. 2007, 369, 186-197. [CrossRef] [PubMed]

24. Yang, L.P.; Zhang, L.; Quan, M.; Ward, J.S.; Ma, Y.L.; Zhou, H.; Rissanen, K.; Jiang, W. A supramolecular system that strictly follows the binding mechanism of conformational selection. Nat. Commun. 2020, 11, 2740. [CrossRef] [PubMed]

25. Tai, D.F.; Jhang, M.H.; Chen, G.Y.; Wang, S.C.; Lu, K.H.; Lee, Y.D.; Liu, H.T. Epitope-cavities generated by molecularly imprinted films measure the coincident response to anthrax protective antigen and its segments. Anal. Chem. 2010, 82, 2290-2293. [CrossRef]

26. Tai, D.F.; Lin, Y.F. Molecularly imprinted cavities template the macrocyclization of tetrapeptides. Chem. Commun. 2008, 43 , 5598-5600. [CrossRef] [PubMed]

27. Zhang, K.; Xia, X.; Deng, S.; Zhong, Y.; Xie, D.; Pan, G.; Wu, J.; Liu, Q.; Wang, X.; Tu, J. Nitrogen-doped sponge Ni fibers as highly efficient electrocatalysts for oxygen evolution reaction. Nanomicro. Lett. 2019, 11, 21. [CrossRef]

28. Tai, D.F.; Lin, C.Y.; Wu, T.Z.; Chen, L.K. Recognition of dengue virus protein using epitope-mediated molecularly imprinted film. Anal. Chem. 2005, 77, 5140-5143. [CrossRef]

29. Feng, L.; Liu, Y.; Hu, J. Molecularly imprinted $\mathrm{TiO}_{2}$ thin film by liquid phase deposition for the determination of $\mathrm{L}$-glutamic acid. Langmuir 2004, 20, 1786-1790. [CrossRef]

30. Das, K.; Penelle, J.; Rotello, V.M. Selective picomolar detection of hexachlorobenzene in water using a quartz crystal microbalance coated with a molecularly imprinted polymer thin film. Langmuir 2003, 19, 3921-3925. [CrossRef]

31. Lieberzeit, P.A.; Afzal, A.; Glanzing, G.; Dickert, F.L. Molecularly imprinted sol-gel nanoparticles for mass-sensitive engine oil degradation sensing. Anal. Bioanal. Chem. 2007, 389, 441-446. [CrossRef] [PubMed]

32. Behjat, V.; Emadifar, R.; Pourhossein, M.; Mohan Rao, U.; Fofana, I.; Najjar, R. Improved monitoring and diagnosis of transformer solid insulation using pertinent chemical indicators. Energies 2021, 14, 3977. [CrossRef]

33. Abu-Siada, A.; Lai, S.P.; Islam, S.M. A novel fuzzy-logic approach for furan estimation in transformer oil. IEEE Trans. Power Deliv. 2012, 27, 469-474. [CrossRef] 